\title{
Experimental Study on Carbonation Resistance and Water Absorbing Property of Concrete Crack with repair
}

\author{
Naoko Tsuchiya ${ }^{1}$ and Kaori Nemoto ${ }^{2}$ \\ ${ }^{1}$ Building Department, National Institute for Land and Infrastructure Management, Tsukuba, Japan, \\ tuchiya-n92ta@mlit.go.jp \\ ${ }^{2}$ Housing Department, National Institute for Land and Infrastructure Management, Tsukuba, Japan, \\ nemoto-k92ta@mlit.go.jp
}

\begin{abstract}
Existing RC Buildings have some cracks and the repairing service might last the buildings for long life. The durability of the RC component is evaluated by several ways as like as carbonation resistance test, permeability test, water penetration test, and so on. Therefore, it need to be measured how much advantage the concrete crack with repair have for the durability. The aim of this paper is to study on advantage of repairing a crack of concrete to the carbonation resistance and the waterabsorbing property by the experimental way. The specimens were prepared in the following point. The finishing (direct finishing and mortal tile finishing), crack width $(0,0.05,0.5$, and $2 \mathrm{~mm})$, and choice repairing or not. All concrete specimens were formed $10 \times 10 \times 20 \mathrm{~cm}$ and those $W / C$ were 0.55 . Then, the specimens were tested by the accelerated carbonation. After 4, 8 and 26weeks accelerated carbonation, the carbonation depth and the carbonation shape of the concretes were measured by $1 \%$ phenolphthalein reaction. Also, the amount of absorbed water from the bottom were measured at 1, 3, 6, 24, 48, 72 and 168h. From the results, the carbonation went rapidly located in $2 \mathrm{~cm}$ around the crack in the case of the no-repair specimens, regardless of any finishing. But in the case of the specimens repaired, it went evenly from the exposure side. And water absorbing test results show a trend that water amount of the concrete with a crack more increase than one of the no-crack concrete.
\end{abstract}

Keywords: Concrete, Crack with Repair, Carbonation Resistance, Water Absorption.

\section{Introduction}

Existing RC buildings ordinary have some cracks. These expand air permeation and water penetration (D. Breysee et al.,), which cause irregular carbonation (Xiao-Hui et al., 2018), and rebar corrosions rapidly.

On the other hand, cracks of the reinforced concrete components sometimes have been repaired, and that might last the buildings for long life.

And now, the durability of the reinforced concrete components is evaluated by several way as like as the carbonation resistance test, the permeability test, the water penetration test, and so on. Therefore, it need to be measured how much advantage the concrete crack with repair have for the durability. The aim of this paper is to study on advantage of repairing a crack of the concrete to the carbonation resistance and the water-absorbing property by the experimental way. 


\section{Specimens}

\subsection{Specimens Type}

Table. 1 shows specimen type. 2 piece of each type specimens were prepared. $10 \times 10 \times 20 \mathrm{~cm}$ rectangular column concretes were made. Many have a man-made crack at the center of oneself, and half of those were repaired.

Table 1. Specimen type.

\begin{tabular}{|c|c|c|c|c|c|c|c|}
\hline No. & Finishing & $\operatorname{crack}(\mathrm{mm})$ & Repair material & No. & Finishing & $\operatorname{crack}(\mathrm{mm})$ & Repair material \\
\hline 1 & Direct finishing & - & - & 8 & Mortal tile & 0.5 & - \\
\hline 2 & Direct finishing & 0.5 & - & 9 & Mortal tile & 0.5 & $\begin{array}{l}\text { Soft epoxy resin } \\
\text { grouting }\end{array}$ \\
\hline 3 & Direct finishing & 0.5 & $\begin{array}{l}\text { Soft enoxy resin } \\
\text { grouting }\end{array}$ & 10 & Mortal tile & $0.5^{* 1}$ & - \\
\hline 4 & Direct finishing & 2 & - & 11 & Mortal tile & 2 & - \\
\hline 5 & Direct finishing & 2 & $\begin{array}{l}\text { U cut and filling with } \\
\text { sealing agent }\end{array}$ & 12 & Mortal tile & 2 & $\begin{array}{l}\text { U cut and filling with } \\
\text { sealing agent }\end{array}$ \\
\hline 6 & Direct finishing & 0.05 & - & 13 & Mortal tile & - & - \\
\hline 7 & Direct finishing & 0.05 & $\begin{array}{l}\text { Coating with flexible } \\
\text { synthetic resin emulsion }\end{array}$ & $\begin{array}{l}* 1 \mathrm{~N} \\
\mathrm{crac}\end{array}$ & $\begin{array}{l}\text { Motal tile ha } \\
\mathrm{k}\end{array}$ & no crack bu & concrete $0.5 \mathrm{~mm}$ \\
\hline
\end{tabular}

\subsection{Mix Proportion of Table 2. shows the mix 3 days after cast. Then

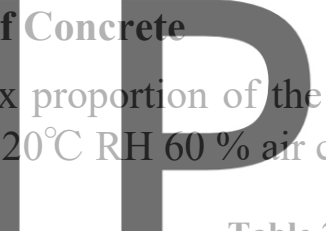 \\ Table 2. Mix pronortion
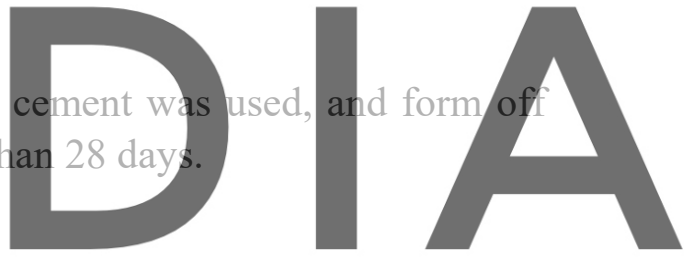

\begin{tabular}{l|l|l|l|l|l|l|l} 
SL & W/C & s/a & BVg & W & C & S & G \\
\hline
\end{tabular}

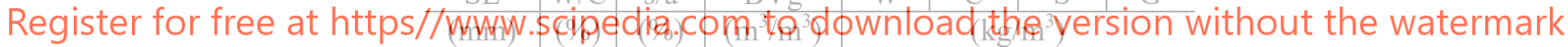
\begin{tabular}{l|l|l|l|l}
18 & 55.0 & 45.8 & 0.59
\end{tabular} \begin{tabular}{l|l|l|l|}
180 & 327 & 793 & 961
\end{tabular}

\subsection{Concrete Crack Width}

The crack width of concrete were $0 \mathrm{~mm}$ (no-crack), $0.05 \mathrm{~mm}, 0.5 \mathrm{~mm}$, and $2 \mathrm{~mm}$. After air curing of the concrete, bending the concrete and put ones together carefully so as to being each crack wide. So, a man-made crack which pass through to another side was at the center of the specimens. Mortal tile also have a crack in response to each concrete crack, except No.10 in Table 1, which mortal tile have no-crack but concrete has a $0.5 \mathrm{~mm}$-wide-crack .

\subsection{Finishing}

Finishing type were direct finishing and mortal tile finishing. Making the mortal tile finishing, $2 \mathrm{~cm}$ mortal were plastered after making concrete crack and cured for not less than 28days by oneself. Except some specimens, mortal tile finishing also have a crack. The crack of mortar bed were made by the way of putting a rubber in and remove it while mortar set. And, the tile were cut ahead and put on mortar bed adjusting a crack. 


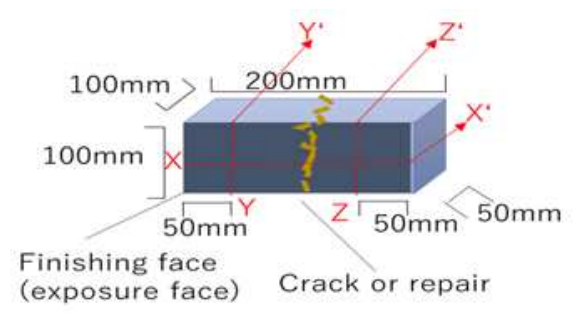

Figure 1. Cut directions after accelerated carbonation test.

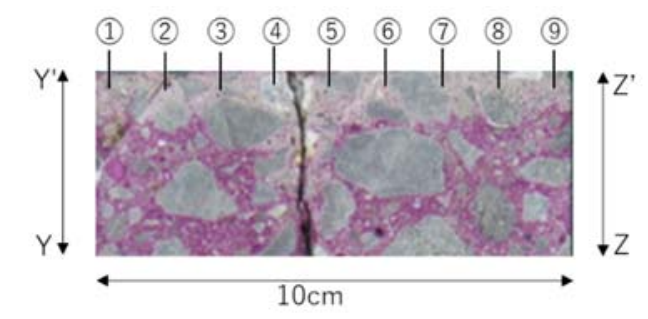

Figure 2. Measurement spots on X-X'cut side.

\subsection{Repair Materials and Methods}

Used repair materials and methods were shown in table 1 . These repair material and method were select corresponding with the crack width. The soft epoxy resin grouting applied for $0.5 \mathrm{~mm}$ crack, $\mathrm{U}$ cut and filling with the sealing agent applied for $2 \mathrm{~mm}$ crack of either finishing. Also, coating with the flexible synthetic resin emulsion were applied for $0.05 \mathrm{~mm}$ crack of direct finishing specimens.

\section{Experiment}

\subsection{Accelerated Carbonation Test}

The specimens were sealed with aluminium tape so that only the finishing face were exposure

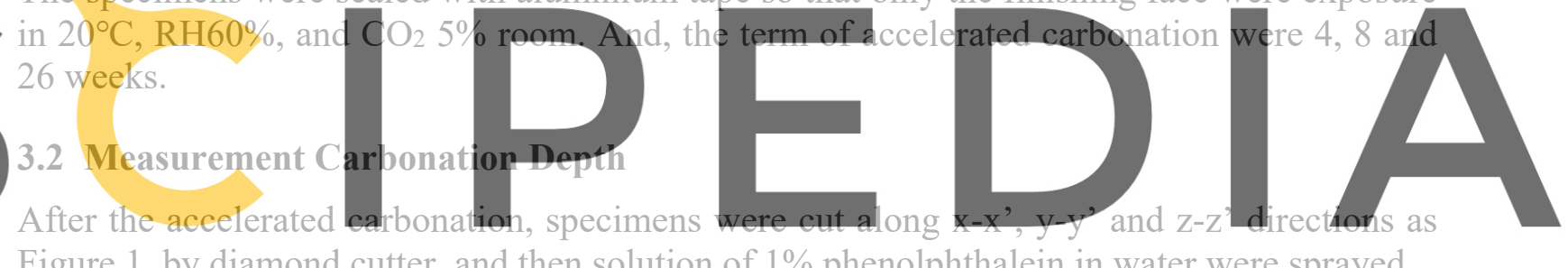

Figure 1. by diamond cutter, and then solution of $1 \%$ phenolphthalein in water were sprayed.

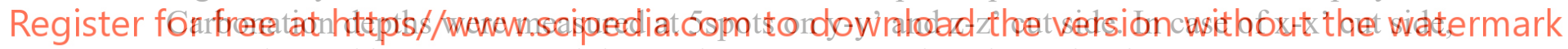

9spots located in $10 \mathrm{~cm}$ around the crack were measured as shown in Figure 2.

\subsection{Water Absorption Test}

After the curing and sealing, specimens were set on the water and measured the amount of the absorbed water at 1,3,6h and 1, 2, 3, 7 days. Water were absorbed from the bottom of the specimens.

\section{Results and Discussion}

\subsection{Carbonation Depth on y-y' and z-z' Cut Side}

This paragraph shows the results of the carbonation depth from exposure side on $y-y^{\prime}$ and $z-z^{\prime}$ cut side. Averaged value of y-y' and z-z' are shown.

\subsubsection{The results of the no-repair case}

Figure 3. shows the carbonation depth on y-y' and z-z' cut side of the no-repair case. In case 


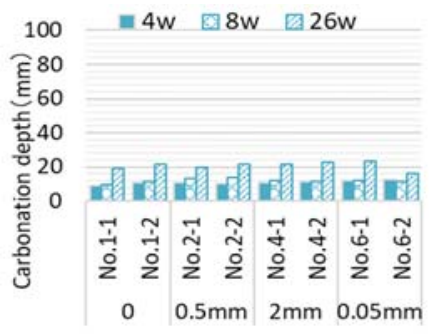

(a)
Direct finishing

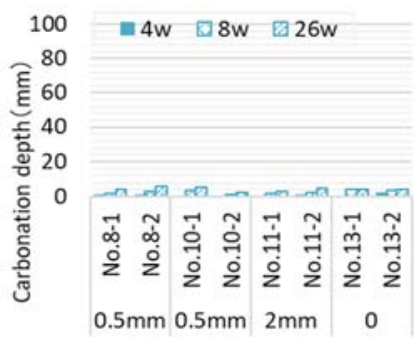

(b) Mortal tile finishing

Figure 3. The carbonation depth on y-y' and z-z' cut side of the no-repair case.

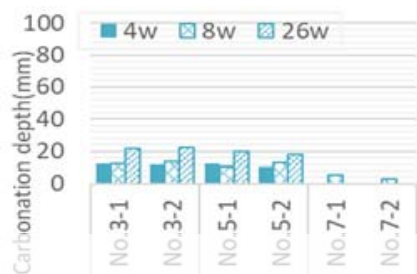

(a) Direct finishing

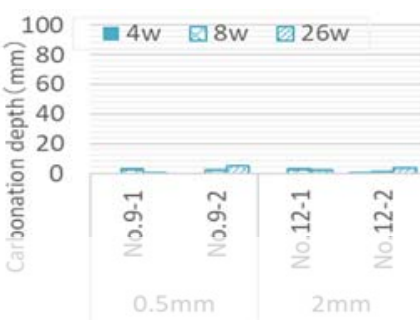

(b) Mortal tile finishing

Figure 4. The carbonation depth on y-y' and z-z' cut side of the repair case.

of the direct finishing, the carbonation depth at 4,8 and 26 weeks were $7 \sim 13 \mathrm{~mm}$, about $12 \mathrm{~mm}$, and $16 \sim 24 \mathrm{~mm}$ respectively. Also, it were under $3 \mathrm{~mm}, 4 \mathrm{~mm}$ and $6 \mathrm{~mm}$ respectively in case of the mortal tile finishing

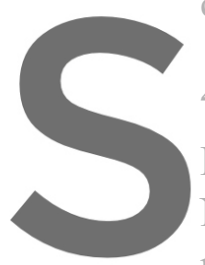

4.1.2 The results of the repair case

Figure 4. shows the carbonation depth on y-

No.7, the carbonation depth at 4,8 and 26 weeks

respectively in case of the direct finishing, that wh
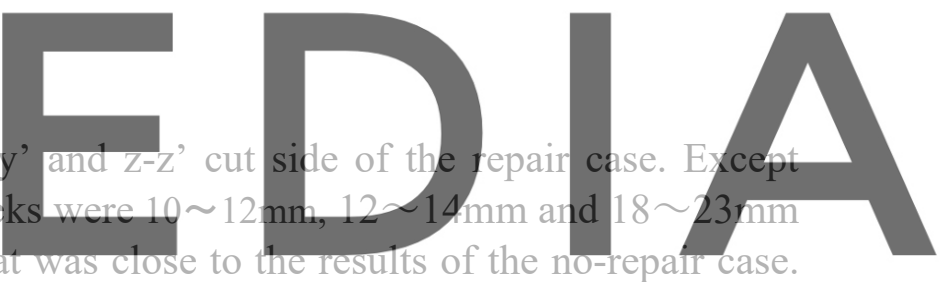

Also, it were under $2 \mathrm{~mm}, 3 \mathrm{~mm}$ and $5 \mathrm{~mm}$ respectively in case of the mortal tile finishing, that

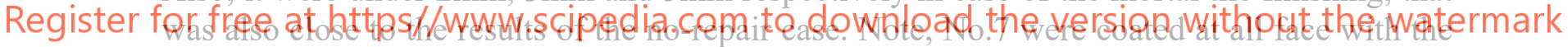

flexible synthetic resin emulsion, so carbonation did not go.

\subsubsection{Discussion}

From the results in Figure 3. and Figure 4., the carbonation depth at each term were same, regardless of repair or not. That shows the process of carbonation located on $5 \mathrm{~cm}$ away from a crack were not relate with a crack or repair.

Add to that, the mortal tile finishing have larger resistance for carbonation than the direct finishing have, as well as the previous studies on preventive effect of finishing materials against carbonation (Kono et al., 2008).

\subsection{Carbonation Depth on $x-x^{\prime}$ Cut Side}

This paragraph shows the results of the carbonation depth from the exposure side on $\mathrm{x}-\mathrm{x}$ ' cut side. In the following figures, the symbol 'Max' means the maximum value in the 9 spots results on $\mathrm{x}-\mathrm{x}$ ' cut side as shown in Figure 2., the symbol 'ave. of $2 \mathrm{~cm}$ around crack' means average of the results of the spots of (4), (5), (6) in Figure 2., and the symbol 'ave. of $10 \mathrm{~cm}$ around crack' means average of 9 spots results. 


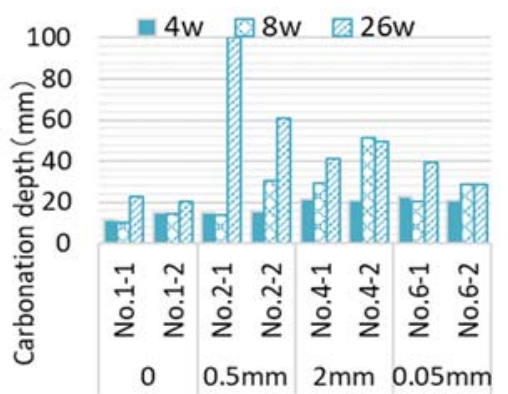

(a1) 'Max'

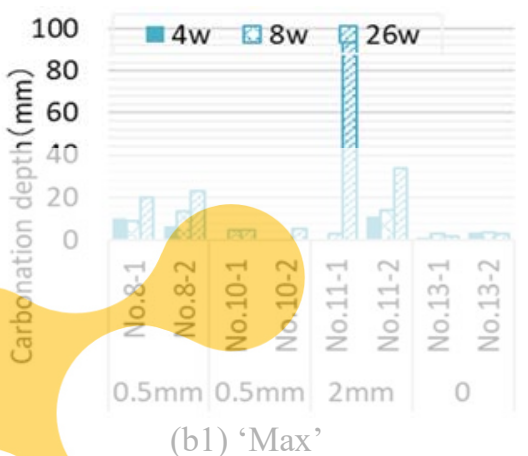

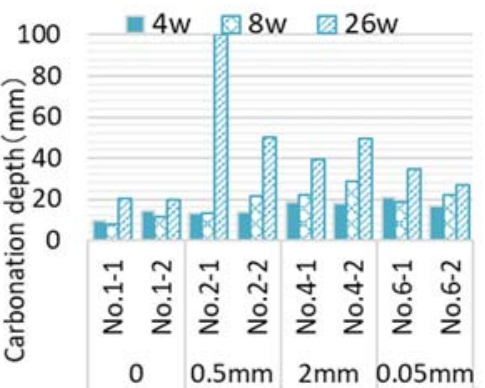

(a2) 'ave. of $2 \mathrm{~cm}$ around a crack'

(a) Direct finishing

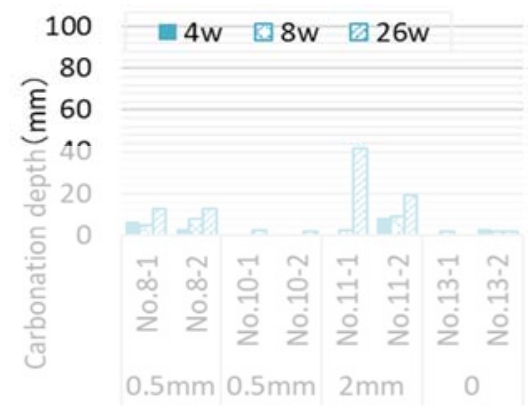

(b2) 'ave. of $2 \mathrm{~cm}$ around a crack'

(b) Mortal tile finishing

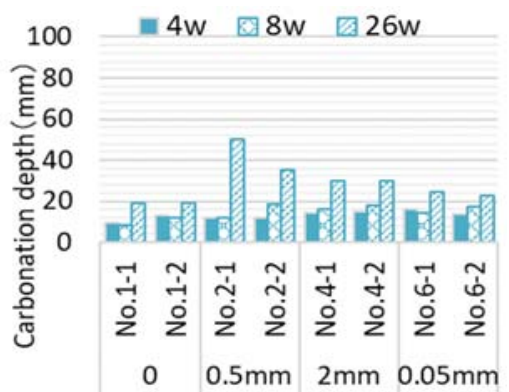

(a3) 'ave. of $10 \mathrm{~cm}$ around a crack'

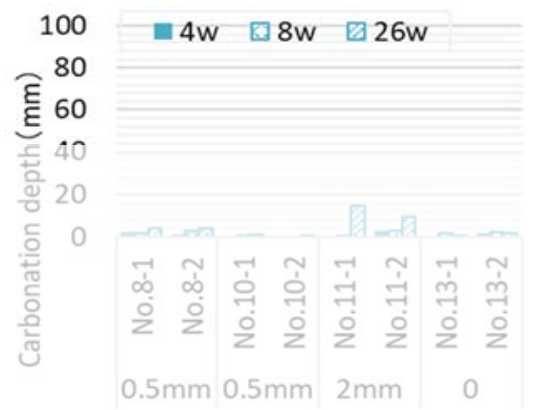

(b3) 'ave. of $10 \mathrm{~cm}$ around a crack'

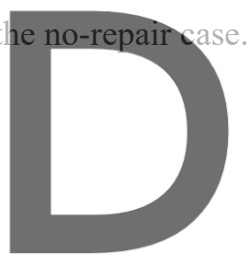

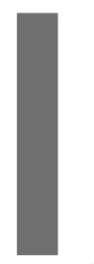

Figure 5. shows the carbonation depth on X-X' cut side of the no-repair case. From the results

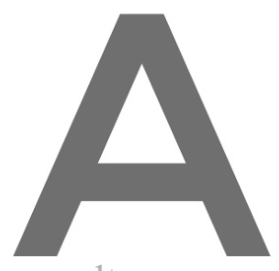

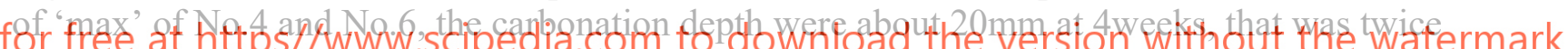

of the result of $y-y^{\prime}$ and $z-z^{\prime}$ cut side at Figure 3 (a). And the results at 8 and 26 weeks were so

large as $30 \mathrm{~mm}$ and $50 \mathrm{~mm}$. Also, the results of 'ave. of $2 \mathrm{~cm}$ around a crack' of No.2, No.4,

and No.6 were about $15 \sim 20 \mathrm{~mm}$ at 4 weeks, that was about half time of the result of y-y' and z-z' cut side. And No.2 at 26weeks were $100 \mathrm{~mm}$. Meanwhile, the result of No.1, which don't have cracks, at 4,8 and 26 weeks were about $10 \mathrm{~mm}, 10 \mathrm{~mm}$ and $20 \mathrm{~mm}$ each, regardless of 'Max', 'ave. of $2 \mathrm{~cm}$ around crack', and 'ave. of $10 \mathrm{~cm}$ around crack', that was close to the results of y-y' and z-z' cut side.

And then, focused on the mortal tile finishing specimens, the carbonation depth of No.8 'Max' at 4, 8 and 26 weeks were about $9 \mathrm{~mm}, 12 \mathrm{~mm}$ and $20 \mathrm{~mm}$, also that of No.8 'ave. of $2 \mathrm{~cm}$ around a crack' were $5 \mathrm{~mm}, 7 \mathrm{~mm}$ and $13 \mathrm{~mm}$, and also that of No.8 'ave. of $10 \mathrm{~cm}$ around a crack' were $3 \mathrm{~mm}, 3 \mathrm{~mm}$ and $4 \mathrm{~mm}$ respectively. Likewise, that of No.11-2 'Max' at 4, 8 and 26 weeks were about $11 \mathrm{~mm}, 14 \mathrm{~mm}$ and $34 \mathrm{~mm}$, also that of No.11-2 'ave. of $2 \mathrm{~cm}$ around a crack' were $9 \mathrm{~mm}, 9 \mathrm{~mm}$ and $20 \mathrm{~mm}$, and also that of No.11-2 'ave. of $10 \mathrm{~cm}$ around a crack' were $3 \mathrm{~mm}, 3 \mathrm{~mm}$ and $10 \mathrm{~mm}$ respectively.

Both 'Max' and 'ave. of $2 \mathrm{~cm}$ around a crack' results were more than double for that of $y-y$ ' and $z-z$ ' cut side as showed in Figure 3. So, these 'Max' and 'ave. of $2 \mathrm{~cm}$ around a crack' results of $x-x$ ' cut side were so larger than that of $y-y$ ' and $z-z$ ' cut side. 


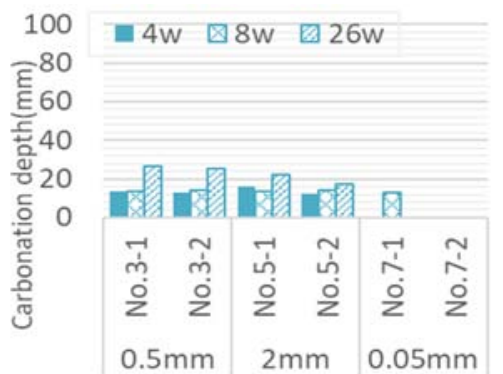

(a1) 'Max'

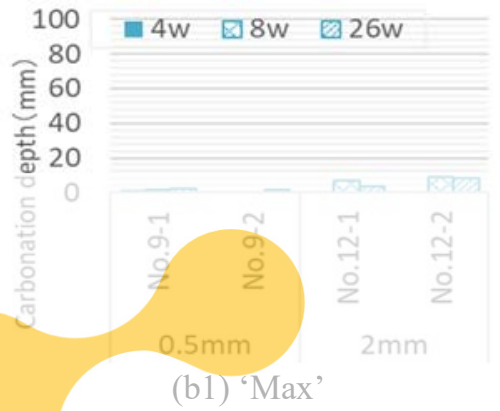

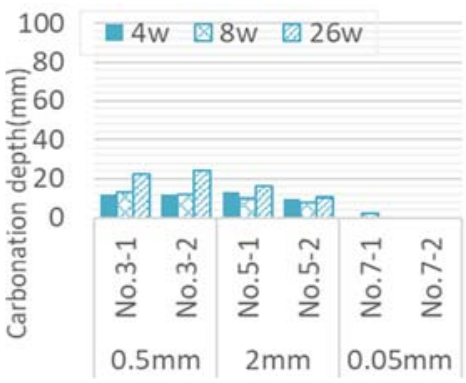

(a2) 'ave. of $2 \mathrm{~cm}$ around a crack'

(a) Direct finishing

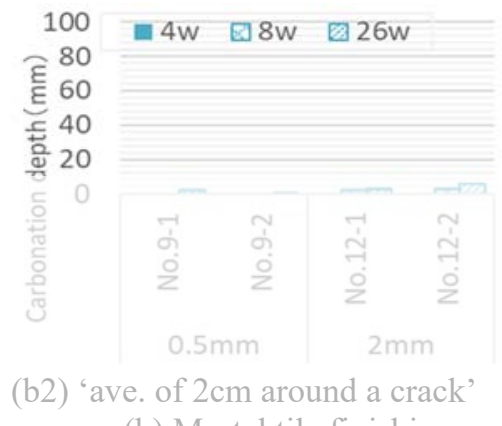

(b) Mortal tile finishing

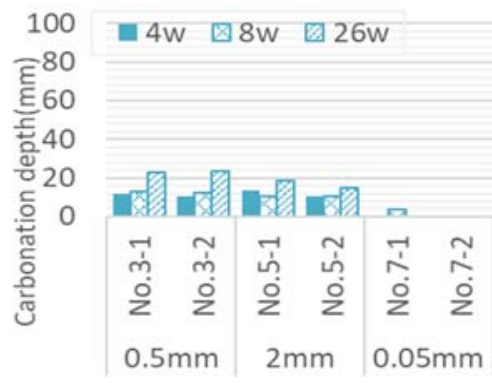

(a3) 'ave. of $10 \mathrm{~cm}$ around a crack'

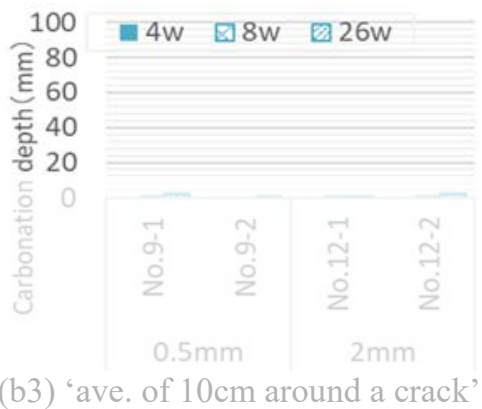

Figure 6. The carbonation depth on $\mathrm{x}-\mathrm{x}$ ' cut side of the repair case.

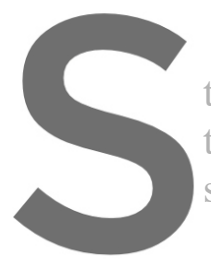

And, results of 'av that of No.13 which hav that carbonation didn't specimen have a concre of $10 \mathrm{~cm}$ around a crac
ve no crack as showed
go at all as $0 \mathrm{~mm}$ at
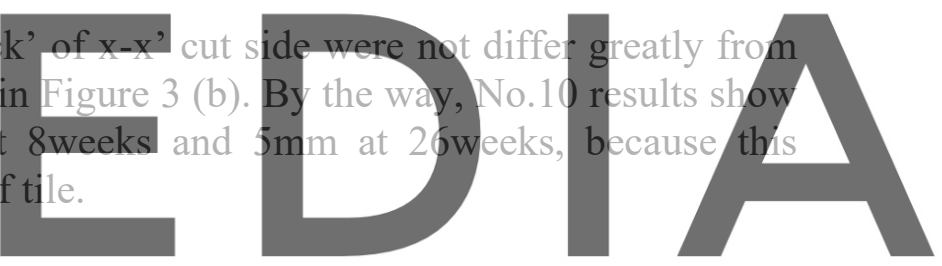

\subsubsection{The results of the repair case}

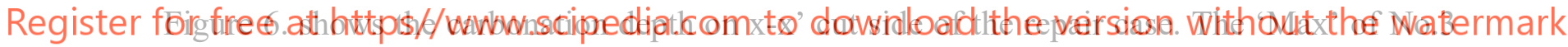
and No.5 at 4, 8 and 26 weeks were about $13 \mathrm{~mm}, 13 \mathrm{~mm}$ and $23 \mathrm{~mm}$, also that of 'ave. of $2 \mathrm{~cm}$ around a crack' were about $11 \mathrm{~mm}, 11 \mathrm{~mm}$ and $18 \mathrm{~mm}$, and also that of 'ave. of $10 \mathrm{~cm}$ around a crack' were $11 \mathrm{~mm}, 11 \mathrm{~mm}$ and $20 \mathrm{~mm}$ respectively. So, these have no difference in measurement field. Add to that, these results were close to the results of No.1 (no-crack case) as well as y-y' and z-z' cut side showed at Figure 4.

And, No.7 were coated at all face with the flexible synthetic resin emulsion, so carbonation have not gone.

As an exception case, the results of No.11 which have $2 \mathrm{~mm}$-wide crack shows the carbonation depth were small until 8weeks but it were large at 26weeks. Because of the repair method that block up by buried only surface layer but the filling didn't reach to deep part, the carbonation went rapid where the filling didn't reach.

And then, focused on the mortal tile finishing, the 'Max' of No.12 at 4, 8 and 26 weeks were about $0 \mathrm{~mm}, 8 \mathrm{~mm}$ and $6 \mathrm{~mm}$, also that of 'ave. of $2 \mathrm{~cm}$ around a crack' were $0 \mathrm{~mm}, 3 \mathrm{~mm}$ and $4 \mathrm{~mm}$, and also, that of 'ave. of $10 \mathrm{~cm}$ around a crack' were $0 \mathrm{~mm}, 1 \mathrm{~mm}$ and $2 \mathrm{~mm}$ respectively. And the carbonation depth of No.9 at 4, 8 and 26 weeks were under $2 \mathrm{~mm}$ regardless of the symbol. These were close to the results of the no-crack case as well as the results of y-y' and z-z' cut side. 


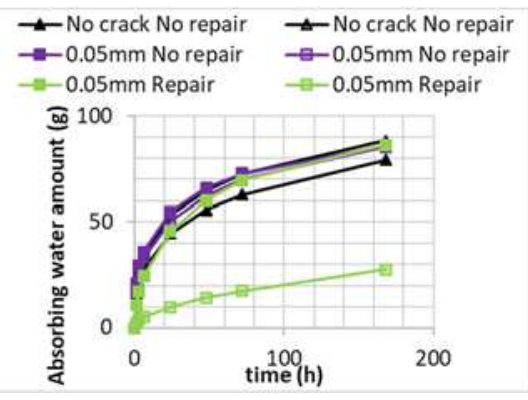

(a1) $0.05 \mathrm{~mm}$-crack-wide

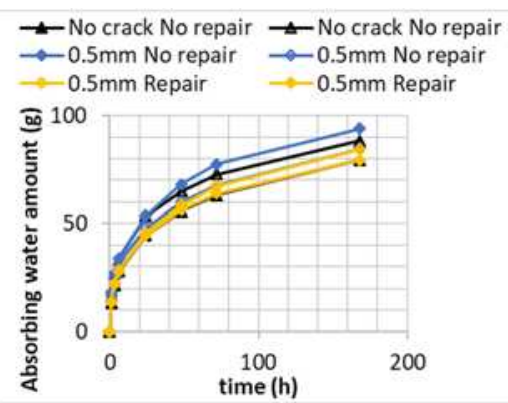

(a2) $0.5 \mathrm{~mm}$-crack-wide

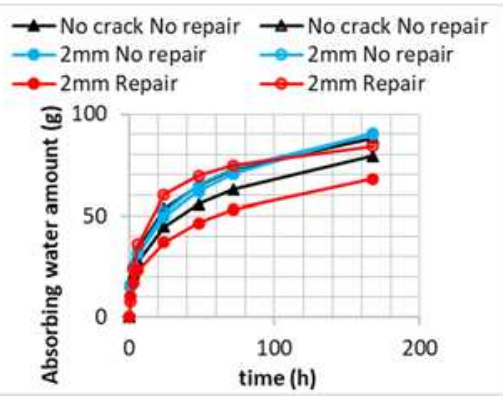

(a3) 2mm-crack-wide

(a) Direct finishing

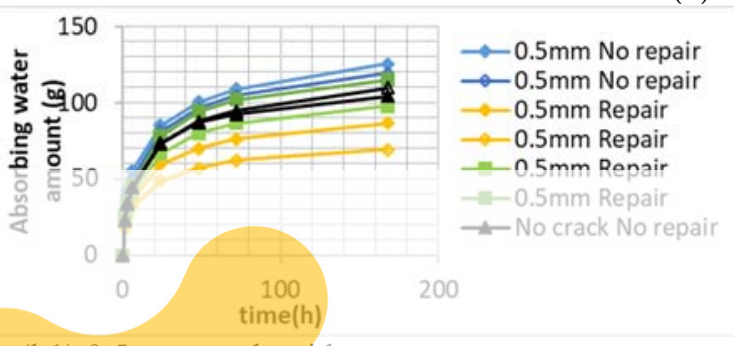

(b1) $0.5 \mathrm{~mm}$-crack-wide

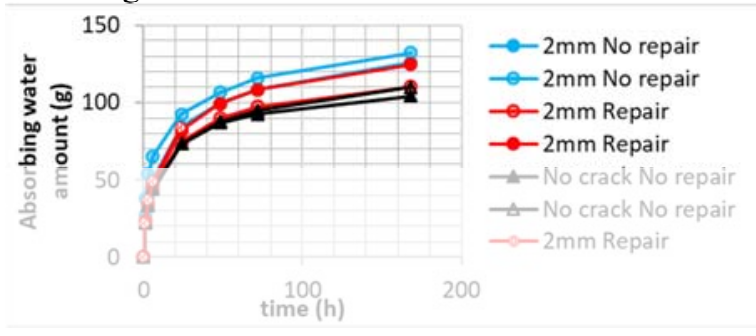

(b2) 2 mm-crack-wide

(b) Mortal tile finishing

Figure 7. The amount of absorbed water

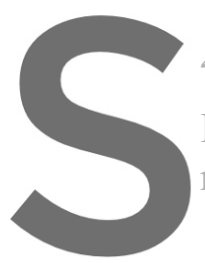

4.2.3 Discussions
In the case of the no-repair, the carbonation went rapidly loca
not rapidly at $10 \mathrm{~cm}$ far from a crack, regardless of any finishit
On the other side, the carbonation of the specimens repaire

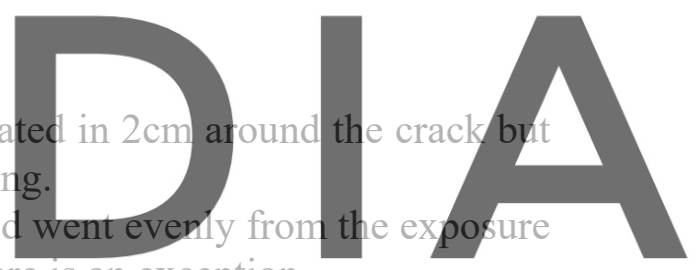

side and that were similarly to the no-crack case, although there is an exception,

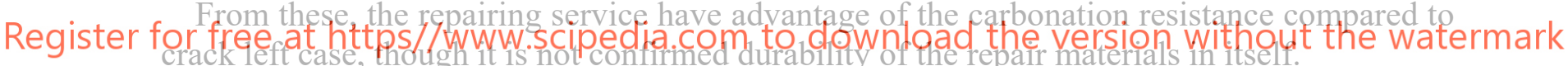

On a side note, the carbonation depth averaged located at $10 \mathrm{~cm}$ around the crack of the no-

repair specimens were close to that of the area far from a crack, and close to the no-crack case. It indicate that the influence of a crack appear little in large mass.

\subsection{The Amount of Water by Absorption Test}

Figure.7 shows the results of the amount of absorbed water from the bottom side. From the results, the amount of absorbed water of the specimens having a crack were bigger than the no-crack specimens. Also, those of the specimens repaired were smaller than that of the norepair, however there were exceptions.

\section{Conclusions}

- The aim of this paper is to study on advantage of the repairing a crack of concrete for the carbonation resistance and water absorption resistance by the experimental way. Then, this paper shows the results of the accelerated carbonation test and water absorption test. Prepared concrete specimens were distinguished as the finishing type, 
the crack width, taking repair or not, and the repair materials. The results in this study indicate as following.

- The mortal tile finishing have larger resistance to the carbonation than the direct finishing have.

- The carbonation went rapidly located in $2 \mathrm{~cm}$ around the crack in the case of the norepair specimens, regardless of any finishing.

- From the results of the repair case, the carbonation went evenly from the exposure side. It was the same process as the no-crack case.

- The amount of the absorbed water of the specimens having a crack were bigger than the no-crack specimens, and some specimens repaired a crack were smaller than that of the no-repair case.

- Many repairing service have advantage of the carbonation resistance as well as water absorption resistance compared to a crack left, though it is not confirmed durability of the repair materials in itself.

ORCID

Naoko Tsuchiya: http://orcid.org/0000-0002-9500-9811

Kaori Nemoto: http://orcid.org/0000-0002-1177-9959

References

D.Breysee and B.Gerard. (1997). Transport of fluids in cracked media, penetration and permeability of concrete, H.W.Reinhardt, ed, R IL

Hosoda A., Hayashi K., Shir surface absorption and pp. 196-203

Kono. M, Nagase K., Tsuduk materials contributing to suppressive of concret
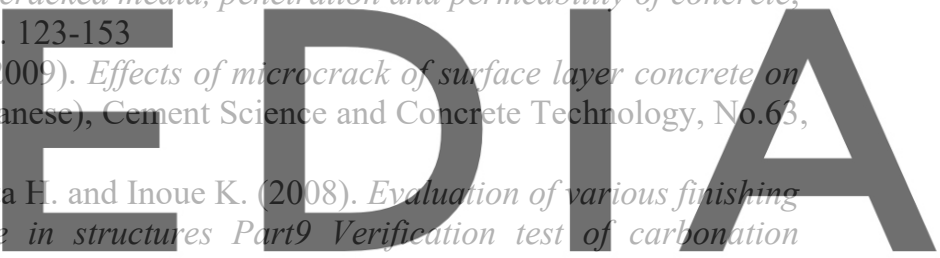

suppressive effects of tile (in Japanese), Summaries of Technical Papers of Annual Meeting of Architectual Institute of Japan (Tohoku), 957-958

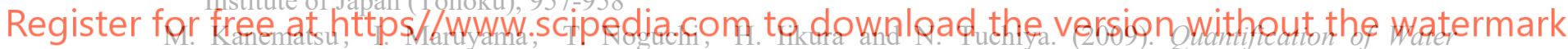

Penetration into Concrete through Cracks by Neutron Radiography, Nuclear Instruments and Methods in Physics Research Section A: Accelerators, Spectrometers, Detectors and Associated Equipment, Vol.605, Issues 1-2, 154-158

Saya M., Takahiro S., Yoshiteru O. and Ichizo K. (2008). Experimental study in carbonation of concrete occurred flexural crack (in Japanese), Proceedings of Annual Convension of Japan Concrete Institute, vol. 30, No.1, 657-662

Hasegawa T., Senbu O., Fukuyama T. and Inoue T. (2017). Deterioration and preventive effects of finishing materials against carbonation and corrosion of reinforcing bars in concrete based on 20year outdoor exposure test using model building (in Japanese), Journal of Structural and Construction Engineering, Vol.82, 733, 337-346

Ujike I., Sato R. and Nagataki S. (1996). A study on deterioration of tightness of cover concrete due to internal cracking based on air pearmiability (in Japanese), Proceedings of the Japan Society of Civil Engineers, No.550, V-33, pp.163-172

Xiao-Hui wang, Dimitri V. Val, Li Zheng and M. Roderick jones. (2018). Influence of loading and cracks on carbonation of RC elementsmade of different concrete types, Construction and Building Materials, Vol.164, $12-28$ 